\title{
Two ways to improve clinical audit's contribution to improving quality of care
}

\author{
Nick Black professor of health services research \\ London School of Hygiene andTropical Medicine, London WC1H 9SH, UK
}

There are two ways that we might improve clinical audit's contribution to improving quality of care. ${ }^{1}$ One is to re-establish a central repository of information on the 50-60 national clinical audits in England. A previous attempt (Directory of Clinical Databases) provided not only information on the data available but also an independent assessment of the quality of the data in the national clinical audit. ${ }^{2}$ Unfortunately, after a few successful years the NHS Information Centre decided not to maintain this database, although it is still archived on the web (http://docdat. ic.nhs.uk/). There is a current initiative, funded by NHS England and led by the Healthcare Quality Improvement Partnership, to create a new resource during $2014 .^{3}$

The second approach is along the lines suggested by Smith. ${ }^{4} \mathrm{I}$ agree that there are many imaginative and enterprising local quality improvement initiatives. A website that highlighted the best and most successful ones would help their dissemination and wider uptake. However, it would be essential that such a resource was kept up to date-often a challenge after initial enthusiasm starts to wane.

Competing interests: I chair the National Advisory Group for Clinical Audit and Enquiries that advises NHS England.

Goldacre B, Heneghan C. Improving, and auditing, access to clinical trial results. BMJ 2014;348:g213. (15 January.)

2 Black N, Payne M. Directory of clinical databases: improving and promoting their use. Qual Safe Health Care 2003;12:348-52.

3 Healthcare Quality Improvement Partnership. NCA quality assessment. 2014. www.hqip. org.uk/nca-quality-assessment/.

4 Smith MD. What about a national clinical audit results database? BMJ 2014;348:g1303.

Cite this as: BMJ 2014;348:g1305

๑ BMJ Publishing Group Ltd 2014 